\title{
Feminicídio: 0 gênero de quem mata e de quem morre
}

\author{
Feminicide: the gender of who kills and who dies
}

\author{
Gabriela Catarina Canal* \\ Naiara Sandi Almeida Alcantara** \\ Isadora Vier Machado***
}

\begin{abstract}
Resumo:
A presente pesquisa, fundamentada pela perspectiva de teóricas feministas e por obras de Direito Penal, Criminologia, Antropologia e Sociologia Jurídica, analisa a estreita relação entre violência doméstica e os feminicídios perpetrados na esfera conjugal e/ ou de intimidade. Objetiva demonstrar a existência de uma intrínseca relação entre o gênero de quem mata e de quem morre ao expor como as relações de poder são capazes de impulsionar e legitimar a posse e o controle sobre o corpo feminino, situando o feminicídio para além de sua carga simbólica, como passo inaugural para 0 reconhecimento da problemática, conferindo-Ihe 0 status de referência para a criação de políticas públicas de enfrentamento à violência de gênero, sem deixar de fazer considerações sobre desejos punitivistas e a consequente demanda por judicialização das pautas feministas no cenário nacional, ressaltando como a Lei do Feminicídio tem contribuído para reascensão deste debate.
\end{abstract}

Palavras-chave: Feminicídio. Gênero. Violência.

\begin{abstract}
:
This research, based on the perspective of feminist theorists and Criminal Law, Criminology, Anthropology and Juridical Sociology works, analyzes the close relationship between domestic violence and feminicides perpetrated in the marital and/or intimacy sphere. It aims to demonstrate the existence of an intrinsic relationship between the gender of who kills and who dies by exposing how power relations are capable of boosting and legitimizing ownership and control over the female body, placing feminicide beyond its symbolic load as an inaugural step to recognize the problematic, coferring it the status of reference for the creation of public policies to face gender violence, without neglecting considerations about punitivist desires and the consequent demand for judicialization of the feminist guidelines in the national scenario, highlighting how the Feminicide Law has contributed to this debate resumption.
\end{abstract}

Key-words: Feminicide. Gender. Violence.

\footnotetext{
* Acadêmica do $5^{\circ}$ ano do curso de Direito pela Universidade Estadual de Maringá (UEM); Estagiária de Direito no Ministério Público Estadual, atuando na Central de Atendimento ao Cidadão.

${ }^{* *}$ Mestre em Ciências Sociais pela Universidade Estadual de Maringá (UEM); Doutoranda em Ciência Política na Universidade Federal do Paraná (UFPR).

*** Doutora em Ciências Humanas pela Universidade Federal de Santa Catarina (UFSC); Professora de Direito Penal e Criminologia, vinculada ao Departamento de Direito Público da Universidade Estadual de Maringá (UEM).
} 


\section{Introdução}

A lei no 13.104/2015, chamada Lei do Feminicídio, alterou 0 art. 121 do Código Penal com a adição do feminicídio como circunstância qualificadora ${ }^{1}$ do crime de homicídio, prevendo situações em que a pena é aumentada de um terço até a metade e incluiu o delito no rol de crimes hediondos. Na letra da lei, feminicídio é a morte de mulheres por razões da condição de sexo feminino, quando o crime envolve violência doméstica e familiar e/ou menosprezo ou discriminação à condição de mulher, cujas margens penais são de 12 a 30 anos de reclusão.

M uito embora se reconheça que 0 fenômeno perpassa 0 ambiente doméstico e familiar, a análise aborda a estreita relação entre violência doméstica e feminicídios perpetrados na esfera conjugal e/ou de intimidade, especialmente entre casais cisgênero e heteroafetivos, pois é no entrecruzamento destas categorias que ocorrem, estatisticamente, a maioria dos feminicídios, recaindo portanto no que concebemos como a existência de uma intrínseca relação entre o gênero de quem mata e de quem morre.

Propõe-se, através de uma revisão da literatura sobre o tema e por meio de análise bibliográfica do que fora produzido (como artigos e dossiês) após a publicação da Lei 13.104/15, situar o feminicídio para além da sua carga simbólica, que tem sido utilizada para embasar as mais severas críticas à nova qualificadora.

Sem deixar de fazer considerações dogmáticas e político-criminais, bem como no que refere à contradição existente dentro dos próprios movimentos feministas quanto à judicialização de suas pautas, pretende-se ressaltar o inegável viés político da adoção da nova qualificadora, que pode ser concebida como referência em conjunto com a Lei Maria da Penha (LMP) para a concepção de políticas públicas de enfrentamento à violência de gênero.

Ademais, pretende-se demonstrar a essencialidade da nomeação dos crimes motivados por razões de gênero, através de um diálogo com as críticas da Teoria Feminista do Direito, bem como o debate para definição de estratégias mais eficientes de prevenção e enfrentamento à violência contra mulheres.

Ao final os resultados e discussões deverão indicar a importância da inclusão do feminicídio no direito brasileiro, demonstrando de que forma a lei contribuiu ou vem

\footnotetext{
${ }^{1}$ São circunstâncias que, por aumentarem o grau de reprovabilidade de determinada conduta, dilatam as margens penais do delito correspondente.
} 
contribuindo para o processo contínuo de enfrentamento à violência de gênero. Deverá ainda comprovar a tese de que há uma relação peculiar entre o gênero de quem mata e de quem morre através de dados estatísticos que comprovam que as mulheres morrem mais "nas mãos" de seus parceiros íntimos e dentro de seus lares, com o fim de posicionar a inserção da qualificadora como uma pauta plausível de apreciação do Poder Judiciário a partir de uma perspectiva de gênero.

"Femicídio" ou "feminicídio" são expressões utilizadas para denominar as mortes violentas de mulheres em razão de gênero, ou seja, motivadas por sua "condição" de mulher, no entanto, não existem consensos em torno desses conceitos, nem no meio acadêmico, político ou legal.

0 termo femicídio (do inglês, femicide) foi utilizado pela primeira vez em 1976, pela Socióloga e feminista anglo-saxã Diana Russel, em um depoimento perante o Tribunal Internacional de Crimes contra Mulheres, em Bruxelas, como uma alternativa contraponto à neutralidade do termo homicídio (RADFORD; RUSSEL, 1992, p. 14), com o objetivo de dar visibilidade à discriminação, opressão e violência à mulher por parte dos homens que, em sua forma mais extrema, resulta na morte.

Na década de 90, Russel e Caputi (1992) aprimoraram o significado do termo atribuindo-Ihe 0 sentido de consequência extrema de um padrão sistemático de violência, universal e estrutural, fundamentado no poder patriarcal das sociedades ocidentais (CAM POS, 2015, p. 105). Em 1992, Russel e Jill Radford lançam a obra Femicide: The Politics of Woman Killing, que se tornou um modelo paradigmático para as discussões em torno das mortes violentas de mulheres, ressaltando se tratarem de crimes de ódio através da expressão "assassinato misógino de mulheres por homens" (RADFORD; RUSSEL, 1992, p. 11).

Para Segato $(2006$, p. 3), a intenção das autoras na referida obra era desmascarar o patriarcado ${ }^{2}$ como uma instituição que sustenta o controle sobre o corpo e a capacidade

\footnotetext{
2 Segundo Carole Pateman (1993, p. 38), o termo "patriarcado" é controverso e problemático. Refere-se a uma forma de poder político. A interpretação tradicional da história do pensamento moderno é de que a teoria e o direito patriarcais foram extintos há muito tempo e praticamente ignorados no século XX. Com o renascimento do movimento feminista nos anos 60 , termo voltou a ser utilizado popular e academicamente. Discutia-se se se tratava do conceito tradicional, de governo paterno, ou uma característica humana universal, se é histórica e culturalmente variável, se estão estabelecidas intrinsecamente na família e na vida social, e ainda, quais as relações existentes entre patriarcado, dominação sexual e capitalismo ou dominação de classe. Muitos/as pesquisadores/as defendem que o termo deveria ser abandonado, justamente por ensejar tantos questionamentos. Para Pateman (1993, p. 39), contudo, “[...] não há nenhum bom motivo para se abandonar os termos patriarcado, patriarcal e patriarcalismo. Grande parte da confusão surge porque 'patriarcado' ainda está por ser desvencilhado doas interpretações patriarcais de seu significado".
} 
punitiva sobre as mulheres, demonstrando a dimensão política de todos os assassinatos destas resultam do controle e capacidade punitiva, sem exceção. Além disso, Radford e Russel (1992) definem "terrorismo sexual" como formas de coação da liberdade feminina que pressionam as mulheres para permanecerem nas posições de submissão e subordinação, previamente estipuladas pela dominação masculina.

A expressão femicídio voltou a ser utilizada nos anos 2000 para denunciar às mortes ocorridas em Ciudad Juarez, no M éxico. Pasinato (2011, p. 225) explica que, nas décadas de 70 e 80 , houve uma política de assentamento de grandes indústrias - "as maquilas" - que se utilizavam da mão de obra feminina ("barata e dócil"), o que provocou rearranjos nos tradicionais papéis de gênero, pois houve um aumento do número de homens desempregados e crescente engajamento de mulheres (jovens e migrantes), que deixavam de cumprir seus papéis de esposas, mães e donas de casa para ingressar no mercado de trabalho, conquistando assim certa autonomia financeira.

Foi diante deste cenário que se iniciou uma onda de assassinatos de mulheres. Os meios de execução e as características das vítimas eram muito semelhantes: a maioria das mulheres mortas eram jovens migrantes, de famílias também nessa condição e operárias industriais, cujos corpos eram jogados em terrenos baldios apresentando marcas de violência sexual, tortura e estrangulamento ou esquartejamento (PASINATO, 2011, p. 226).

Neste contexto, em 2004, a antropóloga e feminista mexicana Lagarde, com 0 propósito de realçar à dimensão política destas mortes, bem como a impunidade e responsabilidade do Estado sobre as mesmas, elaborou o conceito de feminicídio (tradução de femicide para o castelhano), sem deixar de reconhecer que o sexo da vítima e a desigualdade de gênero são as principais características destes crimes. Lagarde utilizou 0 conceito feminicídio para denominar "o conjunto de delitos de lesa-humanidade que contém os crimes e os desaparecimentos de mulheres" (LAGARDE, apud PASINATO, 2011, p. 232).

Atualmente, embora diferentes, os conceitos são tidos como sinônimos para as legislações latino-americanas e à literatura feminista, o que é positivo, pois a unificação do conceito permite maior e melhor articulação política ${ }^{3}$. A categoria "femicídio" foi utilizada no Brasil pela primeira vez por Saffioti e Almeida (1995 apud PASINATO, 2011, p. 240), em

\footnotetext{
${ }^{3}$ Todavia, pode ser uma maneira de limitar a linguagem à medida que elege um termo corrente, que acaba por torná-lo dogmático.
} 
uma análise sobre morte de mulheres nas relações conjugais. Ademais, Pasinato (2011) ressalta que a categoria apareceu novamente em 1998 em um trabalho de Almeida sobre a mesma temática, contudo a legislação brasileira adotou o termo feminicídio, concedendo nomen iures ${ }^{4}$ à morte de mulheres por razões de gênero, quando o crime envolve violência doméstica e familiar e/ou menosprezo ou discriminação à condição de mulher.

\section{Percurso entre Direito e Feminismo: das Raízes Históricas da Violência Contra a Mulher Até a Lei Maria da Penha}

No período entre 1532 (primeira expedição oficial) a 1822 (declaração da independência) o Brasil foi colônia de Portugal, portanto as regras e costumes, bem como 0 sistema jurídico, econômico, político e religioso eram aqueles impostos pela Coroa Portuguesa, através das Ordenações Afonsinas, Manuelinas e Filipinas.

Entre os séculos XVI e XIX a justiça no Brasil seguiu os moldes das Ordenações Filipinas, que concedia ao marido o direito de matar sua esposa caso a surpreendesse em adultério (uxoricídio) ou simplesmente, se houvessem suspeitas ou boatos. 0 marido só poderia ser condenado (a três anos de exílio na África) caso fosse "peão" e o amante, "pessoa de melhor qualidade" (M ELLO, 2017).

Na tradição patriarcal desenvolvida no período da colonização a mulher sempre fora tratada como propriedade, em uma constante relação de submissão: ora do pai, ora do marido. Deveria, portanto, manter-se virgem para assegurar a honra do pai até o casamento, e após este, deveria manter-se fiel para assegurar a honra do marido, sob pena de castigos severos (como privação de alimentos, cárcere privado), enquanto a ele era concedida total liberdade para relacionar-se com outras mulheres.

A infidelidade masculina era/é naturalizada, e a feminina, hostilizada. Criou-se desta forma as bases da dominação masculina institucionalizada e assegurada legalmente, tornando o ambiente doméstico o local mais propício para a prática de violência contra a mulher. A moral era eminentemente sexual. A definição de mulher honesta ou desonesta era dada em razão de sua conduta sexual. Qualquer comportamento tido como ultrajante aos ditames da ordem sexista estabelecida, era suficiente para embasar castigos físicos e psicológicos sem qualquer possibilidade de defesa (MELLO, 2017).

\footnotetext{
${ }^{4}$ Nomen lures é um termo em latim que significa "nome de direito", isto é, a denominação legal de determinado instituto jurídico.
} 
Conforme Mello (2017, p. 87), após a proclamação da independência, mais especificamente em 1830, surge o Código Criminal do Império do Brasil, que aboliu a prerrogativa do marido de matar sua mulher na hipótese de adultério, todavia, caso ocorresse, havia atenuação da pena. 0 adultério era visto como crime. Contudo, o homem não cometia adultério: qualquer relação extraconjugal era tida como concubinato, logo, as alterações não provocaram efeitos substanciais, apenas continuaram reforçando a ideologia patriarcal de posse, controle, domínio e submissão, permitindo que mulheres continuassem sendo assassinadas em larga escala por seus maridos.

Já no século XIX, com a intensificação do capitalismo e consequentemente, com 0 surgimento da burguesia, ocorreram notáveis transformações na sociedade brasileira, que atingiram diretamente as mulheres em suas relações familiares e domésticas. Desta forma, 0 casamento torna-se a principal forma de ascensão social-financeira, e a virgindade, por sua vez, garantia a noiva sua condição político-social que posteriormente permitiria o acesso à herança do marido. Somente as mulheres casadas das classes sociais mais elevadas desfrutavam da vida familiar, e detinham status privilegiado na sociedade (MELLO, 2017). Neste contexto, o Estado "fecha seus olhos" em relação à violência doméstica e familiar contra a mulher, pois a problemática era tida como algo intrínseco ao âmbito privado, que deveria ser solucionado pelos próprios envolvidos.

Após a conquista do direito ao voto, os grupos de feministas passaram por um processo de desarticulação e engajamento com outras causas que tangenciavam questões sociais diversas. Houve, tanto a nível nacional quanto mundial, um período de adormecimento do movimento feminista. É somente na década de 1970 que o movimento feminista ressurge, podendo ser considerado como segundo momento do feminismo no Brasil, associado ao feminismo internacional. Dentre as demandas estavam questões como 0 fim da ditadura e maior participação feminina no mundo do trabalho e da política, passando a ocupar-se de outras questões além do voto. Intensificam-se então, em razão do aumento do número de denúncias, os debates acerca da violência doméstica e familiar contra a mulher.

Em relação aos casos de mortes violentas de mulheres praticadas por companheiros ou ex-companheiros no Brasil, o caso de Ângela Diniz foi um divisor de águas para 0 movimento feminista e de mulheres. Em 1976, após romper o relacionamento com Doca Street, em Búzios-RJ, este a alvejou com quatro tiros. No primeiro julgamento, foi absolvido 
pela tese de "legítima defesa da honra" pois na época, a imprensa se referia à Ângela como a "pantera de M inas" e a defesa a chamou de "vênus lasciva".

Tudo isso levou o movimento feminista a mobilizar-se através do slogan "quem ama não mata" como forma de rejeição à frase dita pelo assassino, de que teria matado por amor, a qual a defesa utilizou para sustentar que se tratava de crime passional, desencadeando uma onda de manifestações populares feministas.

0 movimento feminista no Brasil tornou-se extremamente atuante em todos os âmbitos sociais em prol da emancipação feminina. Depois de muitas conquistas, com demandas pontuais combatendo argumentos que eram utilizados nas primeiras formações do movimento feminino, buscam a manutenção de uma ordem natural onde o homem e a mulher não devem exercer papéis distintos na sociedade. Então, a luta mudou, englobou mais mulheres, tornou-se plural, mas ainda demanda primordialmente por equidade entre os sexos.

Por conseguinte, como movimento social e político, o feminismo trouxe à tona a discussão acerca da violência doméstica, familiar e de gênero, passando a cobrar do Estado uma resposta através da criação de políticas públicas de enfrentamento (MELLO, 2017, p. 91). Dentre várias políticas públicas para mulheres criadas nas últimas décadas, destacam-se o surgimento das Delegacias de Atendimento à Mulher e a promulgação, em 2006, da Lei no 11.340 (Lei Maria da Penha).

Segundo Santos (2010), a criação das Delegacias da Mulher (DDM) em 1985, representa a primeira etapa do processo de absorção, ainda que parcial, das demandas feministas pelo Estado, que implicou em uma intensificação do enfrentamento à violência doméstica no país, mas acabou por reduzir a abordagem feminista à criminalização.

A segunda etapa do processo de absorção/tradução das demandas feministas pelo Estado, é considerada por Santos (2010, p. 160) como a da retradução da criminalização através da ressignificação da violência por meio da criação dos Juizados Especiais Criminais (JECrim). Estes, foram criados pela Lei no 9.099/1995, com o intuito de informalizar a justiça, tornando-a célere e eficiente. Para infrações de "menor potencial ofensivo" ${ }^{5}$, a Lei previa a substituição de penas repressivas por penas alternativas, como prestações pecuniárias (cestas básicas), serviços comunitários e estimulava conciliações.

\footnotetext{
${ }^{5}$ Infrações (crimes e contravenções penais) de menor potencial ofensivo são aquelas cuja pena máxima é inferior a dois anos de detenção.
} 
Neste contexto, os JECrim acabaram retirando a competência de investigação e resolução de conflitos processados nas DDM, pois os crimes de lesão corporal leve e ameaça, cujas penas não ultrapassam dois anos eram os mais registrados nas DDM. Assim, grande parte dos casos processados e julgados pelos JECrim eram originários das delegacias da mulher, o que promoveu a descriminalização e reprivatização da violência contra a mulher.

Diversas críticas foram endereçadas à Lei no 9.099/95 e somente após uma década da promulgação, um consórcio de organizações não-governamentais feministas conseguiram incluir ao texto da Lei Maria da Penha o art. 41, que prevê: "Aos crimes praticados com violência doméstica e familiar contra a mulher, independentemente da pena prevista, não se aplica a Lei n 9.099, de 26 de setembro de 1995" (SANTOS, 2010, p. 161-162). Tem-se assim um salto da indiferença à absorção/tradução ampla das demandas feministas pelo Estado a partir da adoção de uma lei específica de enfrentamento à violência contra as mulheres.

A Lei trouxe significativas transformações nos campos jurídico e político, gerando grande repercussão entre a sociedade, a mídia e o Poder judiciário, constituindo-se como 0 principal marco da judicializaçãa ${ }^{6}$ das demandas feministas. Tratou-se de inegável avanço no tratamento da matéria, entretanto, muitos/as autores/as consideraram errônea a substituição do paradigma da mediação e do consenso pela intervenção penal como forma de resolução de conflitos, que segundo Maria Lucia Karam (2015), apenas reproduz injustiças, seletividade e estigmatização.

M uitos/as críticos/as da lei argumentam que ela contraria a tendência minimalista do Direito Penal e, portanto, não contemplaria o paradigma de gênero pois exclui a mulher do processo de resolução do conflito (AZEVEDO; CELM ER, 2007). Vale ressaltar, todavia, que a Lei Maria da Penha não tem caráter exclusivamente penal. Também contém medidas administrativas, processuais e princípios gerais. Não cria, portanto, novos tipos penais, mas complementos especializantes, exclui institutos despenalizadores, altera penas, estabelece novas qualificadoras e agravantes e institui a possibilidade de decretação da prisão preventiva (M ELLO, 2017).

M as afinal, por que a judicialização da violência doméstica e familiar através da Lei Maria da Penha foi tão relevante ao ponto de justificar a opção pela utilização de uma

\footnotetext{
${ }^{6}$ Rifiotis (2008) conceitua a "judicialização das relações sociais" como o processo de apelo aos serviços de polícia e de um modo geral ao sistema judiciário, que contribui com a ampliação dos litígios alcançados pelo mesmo, desvalorizado outras formas de resolução de conflitos.
} 
intervenção de cunho "criminalizante"? Em uma análise acerca das dimensões normativopenal, protetiva e normativa da referida lei, M achado (2014) demonstra que, para responder a essa questão, é necessário remontar o contexto que antecedeu a Lei.

Em nível normativo-penal, a partir da Lei 10.886/2004 a violência doméstica tornouse uma qualificadora do delito de lesão corporal (art. 129, §9ํ, CP), o que representou, em termos político-criminais, uma regressão ao sistema de proteção às mulheres, pois foi absorvida pela proteção de toda a família, haja vista que a qualificadora estende-se à ascendentes, descendentes, irmãos, cônjuges, companheiros ou qualquer pessoa com que 0 agente tenha convivido. Como a pena máxima não ultrapassava dois anos, pelo art. 61 da Lei 9.099/95, o delito era interpretado como de "menor potencial ofensivo" (M ACHADO, 2014, p. 237), ensejando impunidade e continuidade dos ciclos de violência.

Analisando a complexa relação de incompatibilidade das demandas das mulheres com a lógica do sistema penal, Andrade (2016) preleciona que, na década de 60, os movimentos de mulheres acompanhavam a tendência da Criminologia Crítica de minimização do sistema penal através da descriminalização de condutas de adultério e sedução. Entretanto, nas décadas seguintes, com a criação de centros de acolhimento e, no Brasil, da Delegacia da M ulher (1983), reforçou-se a perspectiva de criminalização no interior do movimento, dando origem ao fenômeno que a autora chama de "publicizaçãopenalização do privado".

$\mathrm{Na}$ década de 80 o movimento feminista europeu e norte americano ${ }^{7}$ provocaram reformas penais que inseriam novos crimes, sob a justificativa da "função simbólica" do Direito Penal, sustentando-o não como forma de punição, mas como meio declaratório de que se trata de condutas socialmente intoleráveis. A finalidade, portanto, é de conscientização pública (ANDRADE, 2016, p. 81).

Contudo, para Andrade (2016), no Brasil esse contexto de reformas era ambíguo, pois ao mesmo tempo em que se pugnava pela descriminalização de determinados crimes (adultério, sedução, aborto), discutia-se a criminalização de condutas até então atípicas (violência doméstica, assédio sexual), recaindo unicamente na função retribucionista de punir e castigar os homens, demonstrando inconsistência da política criminal feminista.

M achado (2014), por sua vez, discorda da posição acima alinhavada, afirmando que o movimento feminista assumiu, por vezes, posição inconstante por razões pragmáticas e

${ }^{7}$ Espanha e Canadá, por exemplo. 
que a Lei Maria da Penha configura-se como "estatuto político complexo", que vai além da função meramente retribucionista, pois, no contexto brasileiro, os anseios por judicialização descendem da ordem estabelecida pelo feminismo latino-americano, em meio a intensificação das lutas por direitos e cidadania. Deste modo, a autora sustenta que as críticas endereçadas à lei são problemáticas, pois focam exclusivamente na dimensão normativo-penal, excluindo as demais.

A autora ainda pontua que a Lei, ao inserir no ordenamento jurídico brasileiro a discussão sobre violência doméstica e familiar contra as mulheres, a partir da categoria de gênero e em relação a direitos humanos, promoveu uma mudança na compreensão do fenômeno, ampliando o conceito de violência para além da física, colocando as mulheres no centro da discussão, de forma oposta ao tratamento dado pelo CP, que tende a absorver sua proteção pela da família. A Lei institui, portanto, um paradoxo: trata-se de um instrumento de controle que, contudo, foi capaz de implementar uma rede articulada de atendimento às mulheres (MACHADO, 2014, p. 252).

Tal paradigma, no contexto brasileiro, promoveu um embate entre a criminologia crítica e a criminologia feminista, cuja problematização estendeu-se à Lei do Feminicídio, e por esta razão, não poderia deixar de ser abordado.

\section{Feminicídio e a Teoria Feminista do Direito: Embate entre a Criminologia Crítica e Feminista}

A inserção do feminicídio no sistema jurídico brasileiro consiste na continuidade do processo de criminalização da violência de gênero, uma tendência latino-americana iniciada nos anos 90, a partir do reconhecimento da especificidade e naturalização dos delitos cometidos contra mulheres, isto é, da violência de gênero, antes ignorada pelo Direito Penal (CAM POS, 2015, p. 105).

Logo após a promulgação da Lei do Feminicídio, diversas críticas the foram endereçadas, tais como a instituição de parâmetros desiguais para homens e mulheres, configurando afronta ao princípio constitucional da isonomia; falhas técnicas e dogmáticas, além de impropriedades político criminais, no sentido da pouca ou nenhuma efetividade da medida no combate à violência de gênero e, por fim, com relação à ineficácia e falência do sistema penal para a solução da problemática. 
No tocante à última das críticas apontadas, uma das mais contundentes considerações foi realizada por Karam (2015). Argumenta a autora que ativistas e movimentos feministas ou de direitos humanos tem sido corresponsáveis pela "desmedida expansão do poder punitivo" que acaba suprimindo direitos humanos por meio de violações aos princípios constitucionais e garantias presentes em declarações internacionais.

Karam (2015) entende que, ao se reivindicar o rigor do sistema penal contra aqueles/as que são apontados/as como responsáveis pela violência de gênero, ativistas e movimentos feministas acabam, paradoxalmente, reafirmando a ideologia patriarcal. Define a Lei Maria da Penha como um lamentável exemplo da cega adesão dos movimentos feministas ao sistema penal, pois considera que sua promulgação não promoveu nenhuma mudança quanto à prevenção de morte de mulheres resultantes de agressões, expondo que os índices variaram muito pouco, estendendo sua crítica à Lei no 13.104/15, a Lei do Feminicídio.

Nesse mesmo sentido, Andrade (2016), defende uma inversão desta polarização: se o sistema penal é ineficaz para proteger às mulheres contra a violência, pois não possui 0 condão preventivo, tão pouco de ressocialização e ainda, promove a vitimização feminina, é necessário que o Direito Penal perca força com a diminuição da criminalização, potencializando-se ao contrário, a cidadania, através dos mecanismos previstos na própria Constituição Federal.

Em contraposição, M ello (2017) entende que a tendência teórica do Direito Penal Mínimo deve ser repensada quanto à questão de gênero, pois, se historicamente o Direito exerceu regulação, controle e violência contra as mulheres, logo, uma minimização do sistema penal não irá garantir a prevenção e o enfrentamento à violência de gênero. Ou seja, não basta minimizar o Direito Penal, é necessário modificá-lo, tornando-o uma importante ferramenta em prol dos direitos humanos das mulheres.

A Lei 11.340/06 inaugurou a tendência de absorção das pautas feministas pelo sistema de justiça, inserindo-as às pautas de políticas públicas brasileiras (BRASIL, 2006). Contudo, algumas das inovações no campo penal e processual penal promovidas pela Lei 11.340/06, notadamente os aumentos de penas e agravantes e a proibição de aplicação de institutos despenalizantes como a composição civil, transação penal e a suspensão condicional do processo, promoveu a intensificação das tensões existentes sobre duas 
perspectivas criminológicas: a criminologia feminista e a criminologia crítica (CAMPOS; CARVALHO, 2011).

Com a promulgação da Lei 13.104/2015, que insere a categoria feminicídio ao Direito Penal brasileiro, tal embate sobre desejos punitivistas e a consequente demanda por judicialização das pautas feministas no cenário nacional adquiriu ainda mais expressão (BRASIL, 2015).

Explicam, Campos e Carvalho (2011, p. 151), que a criminologia crítica, após a virada criminológica causada pelo paradigma do labeling approach ${ }^{8}$ permitiu que o foco da análise criminológica deixasse de ser o criminoso (corrente etiológica) e passasse a ser os mecanismos institucionais de criminalização e os desiguais critérios para aplicação do controle penal que ocasiona a seletividade de populações vulneráveis para caírem nas malhas do sistema penal. Já a criminologia feminista, tendência criminológica preocupada com as relações de gênero, problematiza e faz compreender a lógica androcêntrica que define os mecanismos de controle social e punitivo, denunciando o modo eminentemente masculino de criação, interpretação e aplicação do direito (CAM POS; CARVALHO, 2011).

Desde a década de 70 as mais diversas perspectivas feministas vêm tecendo críticas ao direito, a partir de um pensamento crítico sobre as epistemologias jurídicas, sendo a produção resultante o que caracteriza a denominada "Teoria Feminista do Direito" (CAM POS, 2011), cuja maior contribuição foi realocação da sujeita feminina no ordenamento jurídico brasileiro.

\section{O Gênero de Quem Mata e de Quem M orre}

A grande maioria dos feminicídios, tentados e consumados, são perpetrados por companheiros no âmbito doméstico, mesmo quando as mulheres denunciam as ocorrências, o que denota a grande falha da rede de atendimento à violência doméstica e familiar em evitar as chamadas "mortes anunciadas". 0 feminicídio, nestes casos, geralmente ocorre após o ciclo vicioso próprio de relacionamentos abusivos, que incluem agressões variadas, rompimentos, perdões, novas agressões, chantagens, e assim sucessivamente, em um cenário de negligência estatal e pouca ou nenhuma punição aos agressores (DOSSIÊ FEM INICÍDIO, 2016).

\footnotetext{
8 Trata-se da Teoria do Etiquetamento Social, segundo a qual, os conceitos de crime e criminoso são construções sociais baseadas no controle social do comportamento dos indivíduos.
} 
Não há uma regra que permite identificar, clara e de inequivocamente, se o delito foi ou não motivado pelo desprezo à condição feminina. 0 que se têm são parâmetros, os quais só são percebidos e compreendidos quando se analisa os crimes sob uma perspectiva de gênero. Contudo, de forma geral, é possível observar um padrão em que o corpo da mulher apresenta marcas de violência sexual ou lesões em partes do corpo que remetam à feminilidade, como o rosto, os seios e os genitais, os quais indicam o uso de extrema violência e tortura (QUINTANA, 2014).

A sede da ONU Mulheres no Brasil em parceria com a Secretaria Especial de Políticas Públicas para as Mulheres (SPM), adaptou o protocolo latino americano de assassinato de mulheres por razões de gênero à realidade brasileira dando origem às "Diretrizes Nacionais para Investigar, Processar e Julgar com Perspectiva de Gênero as Mortes Violentas de Mulheres - Feminicídios". De acordo com estas diretrizes, feminicídios íntimos são aqueles cometidos por pessoas ${ }^{9}$ com quem a vítima tinha, ou tenha tido vínculo íntimo.

Embora 0 ambiente doméstico/familiar e as relações íntimas de afeto sejam os principais "lócus" dos feminicídios, estes crimes não ocorrem apenas nessas esferas, afinal também existem feminicídios não íntimos, cometidos por desconhecidos em contextos variados. Estes crimes, muitas vezes, têm suas razões de gênero ocultadas e acabam sendo classificados como decorrentes da criminalidade e violência urbana.

As desigualdades de gênero, sejam elas sociais, políticas, econômicas, ou culturais, além de limitarem 0 acesso das mulheres as mesmas oportunidades dos homens nos campos acadêmicos, profissionais e políticos, também são responsáveis pela idealização, por parte de muitos destes, de um sentimento de posse capaz de torná-las meros objetos sexuais, sob os quais acreditam ter poder e domínio.

É justamente essa situação de subordinação, na maioria das vezes agravada por dependências emocionais e financeiras, a responsável pelos trágicos episódios de feminicídio, que são as mais recorrentes manchetes nos jornais brasileiros. Deste modo, infere-se que o feminicídio tem origem na infração das normas de superioridade masculina que determinam a posse e o controle sobre o corpo feminino. Tratam-se de crimes de poder, que visam a manutenção e reprodução deste (SEGATO, 2006, p. 4).

\footnotetext{
${ }^{9}$ Majoritariamente por homens, todavia podem ser cometidos também por mulheres, na medida em que pessoas do gênero feminino também podem internalizar e reproduzir o machismo em suas relações de foro íntimo.
} 
Levando em conta os apontamentos iniciais feitos acima, passa-se agora a discorrer sobre os dados estatísticos que tendem a confirmar a tese defendida de que mulheres morrem mais "nas mãos" de seus parceiros e ex-parceiros íntimos, ou seja, por quem mais se espera, convencionalmente, amor, companheirismo e respeito e também, dentro de suas próprias casas, tornando possível concluir que o lar é o local mais perigoso para as mulheres.

De acordo com dados estatísticos, pode-se dizer que há uma intrínseca relação entre 0 gênero de quem mata e de quem morre: em 2013 foram registrados 4.762 homicídios de mulheres, e $50.3 \%$ foram cometidos por pessoas que tinham ou tiveram relações íntimas de afeto com a mulher - de acordo com o que estabeleceu a Lei Maria da Penha -, sendo que em 33,2\% destes casos, o autor do crime foi o parceiro ou ex-parceiro, 0 que representa 1.583 mortes, isto é, quatro mulheres mortas por dia.

Os índices quanto ao meio empregado nos homicídios deixam claro o requinte de crueldade próprio dos crimes motivados por razões de gênero: $73,2 \%$ dos homicídios masculinos foram realizados mediante 0 uso de arma de fogo, ao passo que $51,2 \%$ dos homicídios de mulheres ocorreram por meio de estrangulamento, sufocação, ou com instrumentos cortantes, contundentes ou penetrantes (WAISELFISZ, 2015).

Em 2013 o Brasil passou a ocupar a 5ạ posição na lista de países com maiores taxas de homicídios de mulheres, ficando atrás apenas de El Salvador, Colômbia, Guatemala e Rússia. Em 3 anos um aumento de $9 \%$ no número de assassinatos registrados. Se todos os assassinatos viessem a conhecimento das autoridades, sendo possível catalogar com precisão o número de mortes, certamente o país ocuparia uma posição ainda pior.

Ainda segundo o Mapa da Violência de 2015, enquanto o homem sofre com a violência urbana, no espaço público, muitas vezes praticada por outro homem, a mulher sofre mais com a violência no ambiente privado e os agressores são ou foram namorados, maridos ou companheiros. 0 fato de grande parte das mortes ter ocorrido no domićlio da mulher reforça a ideia de que se trata de feminicídios praticados por parceiros íntimo, familiares ou conhecidos da vítima (M ELLO, 2017, p. 127).

Cumpre ressaltar que de acordo com o Mapa da Violência lançado no ano de 2015 em análise comparativa dos dados IBGE entre os anos de 2003 e 2013, verificou-se que enquanto o número de homicídios de mulheres brancas caiu 9,8\% o número de homicídios de mulheres negras aumentou em $54,2 \%$. Foi identificado que a partir do momento que a Lei Maria da Penha entrou em vigor, $2,1 \%$ das mulheres brancas deixaram de ser vitimadas pela 
violência doméstica, enquanto o número de mulheres negras aumentou em 35\%. Esses dados demonstram o quanto a Lei do Feminicídio é essencial para as mulheres negras, pois são elas que mais sofrem em função da combinação de duas variáveis: o sexo e a cor.

Portanto, mulheres negras morrem mais em razão do acúmulo de desigualdades e discriminações. Estas, além de sofrerem com o machismo, sofrem com o racismo estrutural e institucionalizado, opressões essas que são ainda mais expressivas se adicionados os recortes de classe e de gênero.

Soma-se tudo isso ao legado de colonização e escravidão, aos indicadores sociais que denunciam desigualdades e posicionam as mulheres negras na base da pirâmide salarial e de acesso a condições dignas de trabalho, a segregação socioespacial, às dificuldades de acesso tanto à educação básica quanto à educação superior, ao descaso com a saúde e o preconceito enraizado, e o resultado é um Estado totalmente negligente, pois as instituições que deveriam garantir direitos fundamentais acabam atuando como inibidores dos mesmos.

Outro aspecto importante a se analisar é a aplicabilidade da qualificação para mulheres trans e travestis ${ }^{10}$ diante da nomenclatura adotada pela lei, qual seja: "razões da condição de sexo feminino". Isso significa que no Direito Penal, e mais especificamente nos dispositivos de enfrentamento à violência de gênero, quem pode ser reputada como mulher, e consequentemente, sujeita de direito para fins de tutela do bem jurídico da vida na forma qualificada? É notório o fato de que a supressão da expressão "razões de gênero" configurou-se como uma manobra política com o fim de excluir as mulheres transexuais e travestis da esfera de abrangência da lei.

Contudo, a interpretação de que a adoção da expressão "sexo feminino" impediria a aplicação da lei para as mesmas decorre do dualismo existente entre as catego rias "sexo" e "gênero", em que sexo remete às características biológicas e gênero, às sociais. Assim, conforme Fausto-Sterling (2001, p.77) as discussões públicas e científicas consideram o sexo e a natureza como reais, enquanto gênero e cultura seriam construídos, no entanto, tratamse de falsas dicotomias, pois, assim como o gênero, o sexo também é construído socialmente.

\footnotetext{
10 "Mulheres transexuais" ou apenas "mulheres trans", são aquelas pessoas que reivindicam o reconhecimento legal e social como mulher, diferenciando-se, portanto, das pessoas "travestis", que, conforme Jesus (2012, p. 17), vivenciam papéis de gênero feminino, mas não se reconhecem como homens ou mulheres, mas sim como pertencentes a um terceiro gênero ou de um não gênero.
} 
É possível, por conseguinte, concluir que embora a supressão do termo gênero na lei represente um retrocesso teórico, a expressão "condição do sexo feminino" não altera a interpretação da mesma, pois remete, igualmente, às razões de gênero. Em razão da desconstrução do dualismo entre gênero e sexo, da constatação de que este é também uma construção social e considerando que as mortes de mulheres transgêneros são motivadas pela discriminação ao papel social feminino, bem como pelo desprezo àquelas que fogem do padrão cisheteronormativo, está claro que a qualificadora do feminicídio deve ser aplicada as mesmas.

Em março de 2018 a Lei do Feminicídio completou três anos de sua promulgação. Por meio do projeto "Monitor da Violência", decorrente de uma parceria de um influente portal de notícias com o Núcleo de Estudos da Violência da Universidade de São Paulo (USP) e o Fórum Brasileiro de Segurança Pública (FBSP), fora publicada pesquisa que demonstra crescimento no número de vítimas de feminicídios bem como a subnotificação destes casos.

Considerando dados oficiais fornecidos pelos entes federativos brasileiros, a pesquisa aponta para a ocorrência de 4.473 homicídios dolosos no ano de 2017, sendo que destes, 946 foram feminicídios. Em 2016, ocorreram 812 feminicídios de um total de 4.201 homicídios dolosos. Isso significa um aumento de 6,5\% dos casos de feminicídios do ano de 2016 para 2017: a cada duas horas, uma mulher é morta por razões de gênero, ou seja, em média, 12 (doze) mulheres são assassinadas todos os dias no Brasil.

Além das alarmantes taxas de homicídios dolosos e feminicídios, a pesquisa também chama atenção para o alto índice de subnotificação dos referidos dados, admitida pelos próprios entes federativos. Em 2018, três estados - Ceará, Rondônia e Tocantins ainda não possuem dados oficiais compilados sobre feminicídios.

Em 2015, quando sancionada a Lei, tem-se registro da ocorrência de 492 feminicídios em 16 estados brasileiros. Os demais, não possuem dados do primeiro ano e vigência da Lei. Em 2016, a contagem de 812 feminicídios foi oriunda de 20 estados brasileiros e os dados de 2017 (946 feminicídios) dizem respeito à 24 estados. Os entes federativos justificam a falta de dados pela dificuldade em se adequar à nova categoria, com a criação ou reestruturação de departamentos especializados, em relação a atualização dos sistemas de registros ou ainda, no tocante a capacitação da polícia civil, que segue enquadrando os crimes como homicídios dolosos, o que causa invisibilização das reais motivações destes crimes. 
De acordo com a referida pesquisa, o Rio Grande do Norte tem a maior taxa de homicídios contra mulheres (8,4 a cada 100 mil mulheres) e São Paulo tem a menor taxa (2,2 a cada 100 mil mulheres). Em relação ao feminicídio, Roraima não possui nenhum caso registrado, logo, possui a menor taxa, ao passo que o estado do Mato Grosso registra 4,6 feminicídios a cada 100 mil mulheres, tendo portanto a taxa mais alarmante do país.

Estes dados apontam para uma latente dificuldade na mudança do processamento e julgamento dos casos de mortes violentas de mulheres por razões de gênero. Há pouca efetividade na investigação e esclarecimento dos referidos crimes, pois são necessárias investigações conclusivas para que o feminicídio seja assim tipificado. Além disso, ainda há muito desconhecimento, incompreensão ou mesmo indiferença à nova categoria por parte das autoridades policiais. Desta forma, a persecução penal encaminha-se lentamente e sem efetividade, dando ensejo a um constante sentimento de impunidade por parte das vítimas e das famílias das mesmas.

Outra pesquisa que corrobora à tese aqui defendida é o "Raio $X$ do Feminicídio em São Paulo: é possível evitar a morte", realizado pelo Núcleo de Gênero do M inistério Público do Estado de São Paulo (MPSP), sob coordenação da Promotora Valéria Diez Scarance Fernandes. A base de dados da pesquisa consiste em 364 denúncias oferecidas pelo Ministério Público (MP) sobre morte consumada ou tentada de mulheres, em razão da condição de mulher em 121 comarcas paulistas entre março de 2016 e março de 2017.

Dentre os tópicos da pesquisa que auxiliam na elucidação do posicionamento adotado, estão: onde morrem as mulheres e quais armas são utilizadas; quem são as vítimas e sua relação com os sujeitos ativos, por quais motivos as mulheres são mortas e por fim, quanto a existência de medidas protetivas.

0 estudo identificou que em regra, a mulher sofre 0 ataque fatal em casa (66\% dos casos). Os outros 34\% dividem-se em ocorrências: na casa de terceiros (3\%), na casa do réu (3\%), no trajeto da vítima (3\%), no trabalho (5\%), em estabelecimento público $(5 \%)$, hotéis e similares (1\%), via pública (6\%), carro (2\%), local ermo (2\%) ou não identificado (4\%). Então, 2 a cada 3 feminicídios ocorrem na casa da vítima.

No tocante a arma do crime, em $58 \%$ dos casos, o instrumento utilizado foram "armas brancas" (faca, foice, canivete). Foram utilizados instrumentos domésticos (ferramentas, panelas) em $11 \%$ das ocorrências e em $17 \%$ armas de fogo, o que denota a crueldade própria na execução destes crimes. 
Constatou-se ainda que há maior incidência de feminicídios entre pessoas que têm, ou tiveram uma relação de união estável (70\%), seguindo-se as pessoas que são ou eram casadas $(14 \%)$ e os namorados ou ex-namorados (12\%). Outros $4 \%$ correspondem ao percentual referente ao relacionamento extraconjugal, afeto não correspondido e relacionamento com profissional do sexo.

Correlacionado a estes dados têm-se os índices quanto aos motivos para a morte das vítimas: majoritariamente, o vínculo afetivo, quando há separação/rompimento (45\%), atos de ciúmes/machismo (30\%) e discussões banais (17\%). São esses crimes, que ocorrem quando a mulher decide pôr fim ao relacionamento ou decorrentes do ciúme excessivo por parte dos homens que comumente são noticiados pela mídia como "crimes passionais", que dão a falsa ideia de que os agressores "mataram por amor". Isso significa que,

[...] quando o marido perde o controle sobre a mulher, ele se sente no direito de matá-la. A traição, ou a suposta traição, foi e é um dos maiores motivadores de chamados crimes passionais. Em alguns casos, basta o marido/companheiro desconfiar que está sendo traído que o destino de sua parceira será a morte (MELLO, 2017, p. 129).

No tocante à efetividade das medidas protetivas de urgência da Lei Maria da Penha na prevenção do feminicídio, a pesquisa procurou suprir uma lacuna até então não enfrentada. De um universo de 364 casos de feminicídios, em apenas 12 deles (o que representa 3\%), as vítimas possuíam medidas protetivas. Dos 124 casos de feminicídio consumados, em apenas 5 deles a vítima havia registrado Boletim de Ocorrência (BO) contra o agressor. Depreende-se, portanto, que o feminicídio é um crime evitável, pois a maioria das vítimas nunca havia registrado BO tão pouco requerido alguma das medidas protetivas previstas na Lei Maria da Penha.

É evitável porque o feminicídio configura-se como o extremo da violência de gênero, geralmente precedido por um ciclo de violência. Por isso aquelas mortes que ocorrem mesmo quando a vítima busca o Estado, denuncia o agressor e/ ou solicita medidas protetivas são chamadas de "mortes anunciadas", seja por conta da elevada tolerância social à violência de gênero, seja em razão da insuficiência/ineficiência dos serviços públicos de atendimento, segurança e justiça, ou pela negligência de profissionais destes setores, até à impunidade dos agressores e culpabilização das próprias vítimas (DOSSIÊ FEM INICÍDIO, 2016). 
Percebe-se, deste modo, que muito embora ainda sejam incipientes os dados referentes aos feminicídios no Brasil, bem como a dificuldade na adesão e utilização da qualificadora, os dispositivos da Lei M aria da Penha mostram-se de extrema importância na prevenção destes crimes, justificando-se a opção por tratar as Leis 11.340/06 e 13.104/15 para além de seus vieses criminalizantes.

Denotam ainda, que o feminicídio bem como outras formas de violência de gênero mantém-se sob as bases patriarcais e dicotomias de gênero, fazendo com que mulheres continuem sendo subjugadas e submissas à uma ordem de violência estrutural, na qual a menor transgressão da norma masculina de posse e controle, pode custar-Ihe a vida.

\section{Conclusões}

Diante do exposto, tem-se que a realocação da sujeita feminina junto às ciências jurídicas foi a maior contribuição das teorias feministas do Direito, afinal, tornou possível compreender as causas de subordinação e opressão das mulheres, as consequências dessas práticas para a vida social das mesmas, as alternativas de solução da problemática, bem como os constantes desafios das mulheres em meio a uma sociedade misógina, patriarcal e conservadora. Assim, a premissa de que o Direito e o Direito Penal são neutros, ao menos entre as estudiosas feministas, já é um paradigma superado.

De acordo com as análises realizadas verificou-se ainda às que mulheres são mortas, majoritariamente, no âmbito doméstico ou familiar, por homens com quem tem ou tiveram relacionamento íntimo de afeto, o que confirma a existência de uma intrínseca relação entre o gênero de quem mata e de quem morre.

A constatação de que homens matam mulheres retrata quão fortemente as tradições de dominação, sexismo e violência perpassam o espaço-tempo e continuam cerceando a liberdade, dignidade e a vida das mulheres durante todas as fases da vida - 0 que consequentemente restringe e afeta suas vivências enquanto sujeitas de direito.

As mortes de homens e de mulheres são "precificadas" de formas distintas, onde as vítimas de violência doméstica e familiar, bem como de feminicídios, são constantemente culpabilizadas. A adoção da qualificadora de feminicídio, em consonância com as teóricas feministas e teóricas feministas do Direito, surge da necessidade de evidenciar o impacto 
político da desigualdade de gênero que legitima ações de cunho sexista que culminam na violência contra mulheres.

Neste diapasão, a tipificação da qualificadora consiste justamente em uma estratégia para demonstrar as especificidades dos assassinatos contra mulheres, isto é, retirá-los do âmbito genérico de "homicídios" e destacá-los como crimes oriundos do patriarcado.

Com esta pesquisa, espera-se ter contribuído com o registro dos principais posicionamentos acerca do feminicídio no panorama brasileiro bem como com a incitação de discussões futuras. Como visto, uma simples palavra - feminicídio - foi capaz de mobilizar discussões acadêmicas e políticas de diversas ordens. Os frutos dessa análise lançam-se em defesa da adoção deste termo e do empoderamento feminino a partir de sua utilização na busca por um sistema de justiça que se adeque às demandas feministas e não o contrário.

\section{Referências}

ANDRADE, Vera Regina Pereira. Sistema penal máximo x cidadania mínima: códigos da violência na era da globalização. 2. ed. Porto Alegre: Editora Livraria do Advogado, 2016.

AZEVEDO, Elisa Girotti; CELM ER, Rodrigo Ghringhelli. A violência de gênero, produção legislativa e discurso punitivo: uma análise da Lei no 11.340/2006. Boletim do IBCCRIM , São Paulo, ano 14, n. 170, p. 15-17, jan. 2007.

BRASIL. Lei 11.340 de 7 de agosto de 2006. Cria mecanismos para coibir a violência doméstica e familiar contra a mulher. Brasília: Presidência da República, 2006. Disponível em: «ttp://www.planalto.gov.br/ccivil_03/_Ato2004-2006/2006/Lei/L11340.htm>. Acesso em: 7 fev. 2018.

BRASIL. Lei. 13.104 de 9 de março de 2015. Prevê o feminicídio como circunstância qualificadora do delito de homicídio. Brasília: Presidência da República, 2015. Disponível em: http://www.planalto.gov.br/ccivil_03/_Ato2015-2018/2015/lei/L13104.htm. Acesso em: 7 de fev. 2018.

CAM POS, Carmem Hein; CARVALHO, Salo. Tensões atuais entre a criminologia feminista e a criminologia crítica: a experiência brasileira. In: CAM POS, Carmem Hein; CARVALHO, Salo (org.). Lei Maria da Penha: comentada em uma perspectiva jurídico-feminista. Rio de Janeiro: Editora Lumen Juri, 2011. p. 143-169.

CAM POS, Carmen Hein. Feminicídio no Brasil: uma análise crítico-feminista. Sistema Penal \& Violência, Porto Alegre, v. 7, n. 1, p. 103-115, jan./jun. 2015. DOI http://dx.doi.org/10.15448/2177-6784.2015.1.20275. 
CAPUTI, Jane; RUSSEL, Diana. Femicide: sexist terrorism against woman. In: RADFORD, Jill; RUSSEL, Diana. Femicide: the politics of woman killing. New York: Twayne Publishers, 1992.

FAUSTO-STERLING, Anne. Dualismos em duelo. Cadernos Pagu, Campinas, n. 17-18, p. 9 - 79, 2001-2002.

FERNANDES, Valéria Diez Scarance. Raio x do feminicídio em São Paulo: é possível evitar a morte. São Paulo: Núcleo de Gênero do Ministério Público de São Paulo, 2018.

JESUS, Jaqueline Gomes de. Orientações sobre identidade de gênero: conceitos e termos. 2. ed. Brasília: Autor, 2012.

KARAM, M aria Lúcia. Os paradoxais desejos punitivos de ativistas e movimentos feministas. 2015. Disponível em: http://justificando.com/2015/03/13/os-paradoxais-desejos-punitivosde-ativistas-e-movimentos-feministas/. Acesso em: 30 jan. 2018.

MACHADO, Isadora Vier. Para além da judicialização: uma leitura da Lei M aria da Penha (Lei 11.340/06) em três dimensões. In: CARVALHO, Érika Mendes (org.). Direitos fundamentais e sistemas de justiça. Rio de Janeiro: Lumen Juris, 2014. p. 231-255.

M ELLO, Adriana Ramos. Feminicídio: uma análise sociojurídica da violência contra a mulher no Brasil. 2. ed. Rio de Janeiro: LMJ M undo Jurídico, 2017.

PASINATO, Wânia. "Feminicídios" e as mortes de mulheres no Brasil. Cadernos Pagu, Campinas, n. 37, p. 219-246, jul./dez. 2011.

PATEM AN, Carole. O contrato sexual. Rio de Janeiro: Paz e Terra, 1993.

QUINTANA, Carmen Rosa Villa. M odelo de protocolo latino-americano para investigação de mortes violentas de mulheres (femicídios/feminicídios). 2014. Disponível em:

http://www.onumulheres.org.br/wp-

content/uploads/2015/05/protocolo_feminicidio_publicacao.pdf. Acesso em: 7 jan. 2018.

RADFORD, Jill; RUSSELL, Diana. Femicide: the politics of woman killing. New York: Twayne Publishers, 1992.

RIFIOTIS, Theophilos. Judicialização das relações sociais e estratégias de reconhecimento: repensando a "violência conjugal" e a "violência intrafamiliar". Revista Katálysis, Florianópolis, v. 11, n. 2, p. 225-236. Jul./dez. 2008. DOI https://doi.org/10.1590/S141449802008000200008. Disponível em: «ttp://www.scielo.br/scielo.php?script=sci_arttext\&pid=S1414$49802008000200008 \& \operatorname{lng}=p t \& t \mid n g=p t>$. Acesso em: 30 jan. 2018.

SANTOS, Cecília MacDowell. Da delegacia da mulher à Lei M aria da Penha: absorção/tradução de demandas feministas pelo Estado. Revista Crítica de Ciências Sociais, Coimbra, PT, v. 89, p. 153-170. 2010. Disponível em: http://rccs.revues.org/3759. Acesso em: 29 jan. 2018.

SEGATO, Rita Laura. Que és un feminicídio: notas para un debate emergente. Brasília: Universidade de Braślia, 2006. (Série Antropologia, 401). 
WAISELFISZ, Júlio Jacobo. Mapa da violência 2015: homicídio de mulheres no Brasil. Brasília: FLACSO, 2015. Disponível em:

https://www.mapadaviolencia.org.br/mapa2015_mulheres.php. Acesso em: 12 jan. 2018.

Recebido em:19/08/2018

Aceito em: 24/01/2019 